\title{
ANALISIS KOMPARATIF USAHATANI MONOKULTUR TEMBAKAU RAKYAT DAN TUMPANGSARI TEMBAKAU RAKYAT DENGAN CABAI DI KECAMATAN PRINGGABAYA KABUPATEN LOMBOK TIMUR
}

Comparative Analysis of Monokultur Farmingof Tobacco And Tumpangsari's Farming Tobacco With Chili in Subdistrict Pringgabaya Regency East Lombok

\author{
Nurul Aini, Abdullah Usman, IGusti Lanang Parta Tanaya \\ Alumni dan Dosen pada Program Studi Agribisnis, Fakultas Pertanian, Unram \\ Email: anuru1829@mail.com
}

\begin{abstract}
ABSTRAK
Penelitian ini dilaksanakan dengan tujuan: (1) Untuk membandingkann pendapatan usahatani tembakau rakyat antara pola tanam monokultur dan tumpangsari dengan cabai di Kecamatan Pringgabaya Kabupaten Lombok Timur (2) Untuk mengetahui tingkat efisiensi usahatani tembakau rakyat antara pola tanam monokultur dan pola tanam tumpangsari dengan cabai di Kecamatan Pringgabaya Kabupaten Lombok Timur (3) Untuk mengetahui faktor-faktor yang mempengaruhi petani dalam memilih pola tanam pada usahatani tembakau rakyat di Kecamatan Pringgabaya Kabupaten Lombok Timur.

Penelitian ini menggunakan metode deskriptif dan teknik yang digunakan adalah teknik survei yaitu data dikumpulkan dari sejumlah individu (unit sampling) dengan menggunakan daftar pertanyaan yang telah disusun sebelumnya.Unit analisis dalam penelitian ini adalah petani tembakau rakyat pola tanam monokultur dan tumpangsari.Jenis data yang digunakan adalah data kuantitatif dan data kualitatif sedangkan sumber data terdiri dari data primer dan data sekunder.

Hasil penelitian menunjukkan bahwa: (1) Pendapatan usahatani tumpangsari tembakau rakyat dengan cabai lebih besar daripada usahatani monokultur tembakau rakyat yaitu dengan perbandingan 13,34 kali lebih besar pendapatan usahatani tumpangsari tembakau rakyat dengan cabai dari usahatani monokultur tembakau rakyat. (2) Nilai $\mathrm{R} / \mathrm{C}$ ratio pada usahatani tumpangsari tembakau rakyat dengan cabai sebesar 4,38 dan monokultur tembakau sebesar 1,38 dengan selisish 3,00. Kedua pola tanam tersebut menunjukkan layak untuk diusahakan karena masing-masing $\mathrm{R} / \mathrm{C}$ ratio $\geq 1$, akan tetapi pendapatan usahatani tumpangsari tembakau rakyat dengan cabai lebih besar daripada usahatani monokultur tembakau rakyat. (3) Faktor-faktor yang mempengaruhi petani dalam memilih pola tanam pada usahatani tembakau rakyat antara lain pasaran tembakau, perhitungan biaya, jenis tanah, topografi, usaha dan faktor dari bos usaha (pengaruh dari bos), musim, produksi dan keuntungan, waktu dan luas lahan.
\end{abstract}




\begin{abstract}
The research was purposed to:(1) to compared the income of farmer of tobaccobetween with pattern by monoculturefarmand tumpangsari's farm. (2) To determine the level of efficiency of farming community tobacco between with pattern by monoculturefarm and tumpangsari's farmtobacco with chili in District of Pringgabaya Regency of East Lombok (3) To informing about the factors that influence farmers into apply pattern plants of tobacco District of Pringgabaya Regency of East Lombok

The research was uses descriptive method with survey technique, data collected was obtained by each of farmer (sampling unit) by using questionnaire that has been compiled before. The unit of analysis the study is the farmers of tobacco by monoculture and tumpangsari plants pattern. Types of data used are quantitative data and qualitative data while data sources consist of primary data and secondary data.

The results showed that: (1) Income farmer of tobacco by tumpangsari's farm tobacco with chili more than by monoculture farm and the ratio of 13.34 times. (2) The R / C ratio by tumpangsari's farm tobacco with chili was 4.38 and by monoculture farm was 1.38 with agio 3,00 . Both of farm pattern suitableto applied be work because each $\mathrm{R} / \mathrm{C}$ ratio $\geq 1$, but the income of tumpangsari's farm tobacco with chili more than monoculture farming tobacco . (3) the factors was influence the farmer to apply farming pattern tobacco among others, market tobacco, calculation of costs, soil type, topography, business and the factor of the leader of business (the effect of the boss), season, production and profits, time and land area.
\end{abstract}

Kata Kunci : Usahatani, Tembakau Rakyat, Komparatif, Pringgabaya Keywords: Farming, Tobacco, Comparative, Pringgabaya

\title{
PENDAHULUAN
}

Salah satu komoditas perkebunan andalan nasional Indonesia adalah tanaman tembakau.Tanaman tembakau (Nicotiana tobacum.L.) merupakan tanaman semusim, tetapi di dunia pertanian termasuk dalam golongan tanaman perkebunan dan tidak termasuk golongan tanaman pangan.Tembakau (daunnya) digunakan sebagai bahan pembuatan rokok (Hanum, 2008).Salah satu sentra produksi tembakau rakyat di Kabupaten Lombok Timur yaitu Kecamatan Pringgabaya.Berdasarkan data BPS (2016) menyatakan Kecamatan Pringgabaya dari tahun 2013 sampai dengan tahun 2015 mengalami penurunan produksi yaitu $1.257,00$ ton (2013) menjadi 545,83 ton (2015). Penurunan produksi tembakau rakyat disebabkan dengan bebagai permasalahan salah satu diantaranya yaitu 
penurunan luas area tanam.Penurunan luas area tanam diduga adanya keterkaitan dengan dua pola tanam yaitu pola tanam monokultur dan tumpangsari. Sistem tanam tumpangsari adalah salah satu usaha sistem tanam dimana terdapat dua atau lebih jenis tanaman yang berbeda ditanam secara bersamaan dalam waktu relatif sama atau berbeda dengan penanaman berseling-seling dan jarak tanam teratur pada sebidang tanah yang sama (Warsana, 2009dalam Pemanasari, 2012). Menurut Gomez (1983) secara tradisional tumpangsari digunakan untuk meningkatkan diversitas produk tanaman dan stabilitas hasil tanaman.Keuntungan yang diperoleh dengan penanaman secara tumpangsari diantaranya yaitu memudahkan pemeliharaan, memperkecil resiko gagal panen, hemat dalam pemakaian sarana produksi danmampu meningkatkan efisiensi penggunaan lahan (Beets, 1982).Petani di Kecamatan Pringgabaya beralih kepola tanam tumpangsari karena telah diketahui bahwa tumpangsari dapat memberikan hasil yang lebih tinggi dibandingkan dengan monokultur.Hal ini sesuai dengan pernyataan bahwa pertanaman tumpangsari lebih banyak diketahui mampu memberikan hasiltanaman secara keseluruhan yang lebih tinggi dibandingkan monokultur, apabila tepat dalam pemilihan spesies tanaman yang dirumpangsarikan (Anonim, 1998).

Tujuan penelitian ini adalah: (1) Untuk membandingkann pendapatan usahatani monokultur tembakau rakyat dan tumpangsari tembakau rakyat dengan cabai di Kecamatan Pringgabaya Kabupaten Lombok Timur (2) Untuk mengetahui tingkat efisiensi usahatani monokultur tembakau rakyat da tumpangsari tembakau rakyat dengan cabai di Kecamatan Pringgabaya Kabupaten Lombok Timur (3) Untuk mengetahui faktor-faktor yang mempengaruhi petani dalam memilih pola tanam pada usahatani tembakau rakyat di Kecamatan Pringgabaya Kabupaten Lombok Timur.

\section{METODE PENELITIAN}

Metode yang digunakan dalam penelitian ini adalah metode deskriptif dan teknik pengumpulan data yang digunakan adalah teknik survei.Unit analisis dalam penelitian ini adalah petani tembakau rakyat pola tanam monokultur tembakau rakyat dan tumpangsari tembakau rakyat dengan cabai di Kecamatan Pringgabaya Kabupaten Lombok Timur.Penentuan daerah sampel penelitian ditentukan secara Purposive Sampling.Jumlah responden dalam penelitian ini adalah 60 orang petani, jumlah tersebut ditentukan secara Quota Sampling dengan masing-masing desa sebanyak 30 responden.Pengambilan responden dilakukan dengan caraAccidental Samplingyaitu peneliti mengumpulkan sampel dari unit sampel yang kebetulan ditemuinya atau mereka yang mudah ditemui dan dijangkau. Setelah jumlahnya mencukupi maka pengambilan sampel dihentikan (Abdullah 
dan Sutanto, 2015dalam Robis, 2016). Jenis data yang digunakan adalah data kuantitatif dan data kualitatif sedangkan sumber data terdiri dari data primer dan data sekunder.Untuk menghitung biaya produksi, penerimaan, pendapatan dan efisiensi dianalisis bersifat kuantitatif dengan menggunakan rumus sebagai berikut:

1. Biaya produksi menggunakan rumus (Suratiyah, 2006)

$$
\mathbf{T C}=\mathbf{T F C}+\mathbf{T V C}
$$

Keterangan :

$$
\mathrm{TC}=\text { Total Cost (Biaya Total) }
$$

$\mathrm{TFC}=$ Total Fixed Cost (Total Biaya Tetap)

$\mathrm{TVC}=$ Total Variable Cost (Total Biaya Tidak Tetap)

2. Penerimaan usahatani menggunakan rumus (Suratiyah, 2006)

$$
\mathbf{T R}=\mathbf{Y} . \mathbf{P y}
$$

Keterangan :

$\mathrm{TR}=$ Total Revenue (Penerimaan Total)

$\mathrm{Y}=$ Jumlah produksi (Pohon)

Py $=$ Harga produksi (Rp/Pohon)

3. Pendapatan usahatani menggunakan rumus (Suratiyah, 2006)

$$
\mathbf{I}=\mathbf{T R}-\mathbf{T C}
$$

Keterangan :

I = Income (Pendapatan)

$\mathrm{TR}=$ Total Revenue (Penerimaan Total)

$\mathrm{TC}=$ Total Cost (Biaya Total)

4. Efisiensi usahatani menggunakan rumus (soekartawi, 1995)

$$
R / C^{\text {Ratio }}=\frac{R}{C}
$$

Keterangan :

$$
\begin{aligned}
& \mathrm{R}=\text { Besarnya penerimaan usahatani } \\
& \mathrm{C}=\text { Besarnya biaya usahatani yang dikeluarkan }
\end{aligned}
$$

Untuk mengetahui masalah dan alasan petani usahatani tembakau rakyat dalam memilih pola tanam antar pola tanam monokultur tembakau rakyat dan tumpangsari tembakau rakyat dengan cabai dilakukan dengan metode kualitatif.Sedangkan untuk mengetahui perbedaan biaya, pendapatan dan efisiensi antara pola tanam monokultur tembakau rakyat dan tumpangsari tembakau rakyat dengan cabai, dilakukan analisis mengunakan pengujian hipotesis dengan taraf 5\%.Dalam pengujian hipotesis dilakukan analisis menggunakan uji-t, terlebih dahulu dilakukan uji-F untuk mengetahui apakah kedua sampel tersebut homogen atau tidak. 


\section{HASIL DAN PEMBAHASAN}

\section{Penggunaan Sarana Produksi dan Tenaga Kerja \\ 1.1.Penggunaan Sarana Produksi}

Sarana produksi yang digunakan pada usahatani monokultur tembakau rakyat dan tumpangsari tembakau rakyat dengan cabai meliputi bibit (tembakau: jenis tembakau tanjung dan tembakau kasturi, dan bibit cabai yaitu jenis cabai rawit), pupuk anorganik, dan pestisida.

Tabel 1. Penggunaan Sarana Produksi pada Usahatani Monokultur Tembakau Rakyat dan Tumpangsari Tembakau Rakyat dengan Cabai di Kecamatan Pringgabaya Kabupaten Lombok Timur, Tahun 2016

\begin{tabular}{|c|c|c|}
\hline \multirow[t]{2}{*}{ Urain } & $\begin{array}{c}\text { Monokultur Tembakau } \\
\text { Rakyat }\end{array}$ & $\begin{array}{l}\text { Tumpangsari Tembakau } \\
\text { Rakyat dengan Cabai }\end{array}$ \\
\hline & Per Ha & Per $\mathrm{Ha}$ \\
\hline a. Bibit & 221,32 & 414,13 \\
\hline b. Pupuk & 1083,59 & 1430,77 \\
\hline c. Pestisida & 7 & 13,49 \\
\hline
\end{tabular}

Berdasarkan Tabel 1 dapat diketahui bahwa rata-rata total bibit, pupuk dan pestisida yang digunakan dalam usahatani tumpangsari tembakau rakyat dengan cabai lebih besar daripada usahatani monokultur tembakau rakyat.

\subsection{Rata-rata Penggunaan Tenaga Kerja}

Perhitungan penggunaan tenaga kerja dalam penelitian ini menggunakan satuan HKO (Hari Kerja Orang). Tenaga kerja didaerah penelitan diberi upah sebesar Rp. 60.000 atau Rp. 70.000 untuk tenaga kerja pria dan Rp.50.000 untuk tenaga kerja wanita, dengan jam kerja selama 7 jam.

Tabel 2. Penggunaan Tenaga Kerjapada Usahatani Monokultur Tembakau Rakyat dan Tumpangsari Tembakau Rakyat dengan Cabai di Kecamatan Pringgabaya Kabupaten Lombok Timur, Tahun 2016

\begin{tabular}{|c|c|c|c|c|}
\hline \multirow[t]{2}{*}{ Keterangan } & \multicolumn{2}{|c|}{$\begin{array}{c}\text { Monokultur Tembakau } \\
\text { Rakyat }\end{array}$} & \multicolumn{2}{|c|}{$\begin{array}{l}\text { Tumpangsari Tembakau } \\
\text { Rakyat dengan Cabai }\end{array}$} \\
\hline & Per $\mathrm{Ha}$ & $\%$ & Per Ha & $\%$ \\
\hline Tenaga Kerja Dalam Keluarga & 43,82 & 23,11 & 87,22 & 19,1 \\
\hline Tenaga Kerja Luar Keluarga & 145,8 & 76,89 & 369,34 & 80,9 \\
\hline Total Tenaga Kerja & 189,62 & 100 & 456,56 & 100 \\
\hline
\end{tabular}

Sumber: Data Primer Diolah

Berdasarkan Tabel 2 menunjukkan bahwa total penggunaan tenaga kerja pola tanam tumpangsari tembakau rakyat dengan cabai lebih besar dibandingkan dengan pola tanam monokultur tembakau rakyat hal ini karena 
proses budidaya pada usahatani tumpangsari tembakau rakyat dengan cabai sedikit berbeda dengan budidaya pada usahatani monokultur tembakau rakyat, ada beberapa kegiatan usahatani yang tidak dilakukan secara bersamaan misalnya pada penanaman dan pemanenan.

\section{Rata-rata Total Biaya}

Total biaya merupakan keseluruhan biaya yang dikeluarkan petani untuk pembiayaan usahataninya yang terdiri dari biaya sarana produksi, biaya tenaga kerja, biaya tetap dan biaya lain-lain.

Tabel 3. Rata-rata Total Biaya pada Usahatani Monokultur Tembakau Rakyat dan Tumpangsari Tembakau Rakyat dengan Cabai di Kecamatan Pringgabaya Kabupaten Lombok Timur, Tahun 2016

\begin{tabular}{|l|c|r|}
\hline \multirow{2}{*}{ Keterangan } & $\begin{array}{c}\text { Monokultur } \\
\text { tembakau rakyat }\end{array}$ & $\begin{array}{c}\text { Tumpangsari tembakau } \\
\text { rakyat dengan cabai }\end{array}$ \\
\cline { 2 - 3 } & Per Ha & Per Ha \\
\hline Total Biaya Saprodi & 3.605 .702 & 5.707 .924 \\
\hline Total Biaya Tenaga Kerja & 12.514 .912 & 27.681 .818 \\
\hline Biaya Tetap dan Lain-lain & 7.962 .724 & 3.055 .918 \\
\hline Total Biaya & 24.083 .338 & 36.445 .660 \\
\hline
\end{tabular}

Sumber: Data Primer Diolah

Berdasarkan Tabel 3 menunjukkan bahwa komponen biaya terbesar yang dikeluarkan petani adalah biaya tenaga kerja.Besarnya biaya tenaga kerja yang dikeluarkan oleh petani karena banyaknya kegiatan usahatani yang membutuhkan banyak tenaga kerja dan curahan hari kerja yang cukup lama. Selain itu, proses usahatani dari persiapan lahan hingga proses pemanenan semuanya menggunakan tenaga manusia. Rata-rata total biaya usahatani tumpangsari tembakau rakyat dengan cabai lebih besar daripada usahatani monokultur tembakau rakyat. Hal ini karena biaya untuk pegadaan saprodi dan upah tenaga kerja pada usahatani tumpangsari tembakau rakyat dengan cabai lebih besar.

\section{Analisis Perbandingan Penerimaan, Biaya, Pendapatan dan Efisiensi}

Penerimaan dalam penelitian ini adalah nilai uang yang diterima petani dari hasil produksi usahatani, diperoleh dari hasil perkalian antara jumlah produksi dengan harga jual produk per kwintal pada tanaman tembakau rakyat dan hasil perkalian antara jumlah produksi dengan harga jual produk per kwintal pada tanaman cabai. 
Tabel 4. Perbandingan Penerimaan, Biaya, Pendapatan dan Efisiensi Usahatani Monokultur Tembakau Rakyat dan Tumpangsari Tembakau Rakyat dengan Cabai di Kecamatan Pringgabaya Kabupaten Lombok Timur, Tahun 2016

\begin{tabular}{|c|c|c|c|}
\hline \multirow[b]{2}{*}{ Keterangan } & \multicolumn{2}{|c|}{ Pola Tanam } & \multirow[b]{2}{*}{ Selisih } \\
\hline & $\begin{array}{c}\text { Monokultur } \\
\text { tembakau rakyat }\end{array}$ & $\begin{array}{c}\text { Tumpangsari } \\
\text { tembakau } \\
\text { rakyat dengan } \\
\text { cabai }\end{array}$ & \\
\hline \multicolumn{4}{|l|}{ Produksi } \\
\hline a. Tembakau rakyat $(\mathrm{Kw})$ & 107,59 & 103,80 & 3,79 \\
\hline b. Cabai (Kw) & 0,00 & 36,90 & 36,90 \\
\hline \multicolumn{4}{|l|}{ Harga } \\
\hline $\begin{array}{l}\text { a. Tembakau rakyat } \\
\text { (Rp/Kw) }\end{array}$ & $309.666,70$ & $257.833,33$ & $51.833,37$ \\
\hline b. Cabai (Rp/Kw) & 0,00 & $3.600 .000,00$ & $3.600 .000,00$ \\
\hline Total Penerimaan $(\mathrm{Rp})$ & $33.316 .330,41$ & $159.604 .315,38$ & $126.287 .984,97$ \\
\hline Total Biaya (Rp) & $24.083 .338,18$ & $36.445 .660,18$ & $12.362 .322,00$ \\
\hline Pendapatan & $9.232 .992,23$ & $123.158 .655,20$ & $113.925 .662,97$ \\
\hline $\mathrm{R} / \mathrm{C}$ ratio & 1,38 & 4,38 & 3,00 \\
\hline
\end{tabular}

Sumber: Data Primer Diolah

Berdasarkan Tabel 4 menunjukkan bahwa rata-rata penerimaan pola tanam tumpangsari tembakau rakyat dengan cabai lebih besar daripada usahatani monokultur tembakau rakyat hal ini karena petani mendapatkan penerimaan dari dua jenis komoditi dalam satu lahan.

Pendapatan usahatani tumpangsari tembakau rakyat dengan cabai lebih besar daripada usahatani monokultur tembakau rakyak.Hal ini karena usahatani monokultur tembakau rakyat tidak mendapatkan penerimaan tambahan seperti usahatani tumpangsari tembakau rakyat dengan cabai sehingga faktor yang membedakan pendapatan jauh berbeda antara keudua pola tanam adalah jumlah komoditi yang ditanam dalam satu lahan.

Nilai R/C ratio pada usahatani tumpangsari tembakau rakyat dengan cabai sebesar 4,38 sedangkan pada usahatani monokultur tembakau sebesar 1,38 dengan selisish 3,00. Kedua pola tanam tersebut menunjukkan layak untuk diusahakan karena masing-masing $\mathrm{R} / \mathrm{C}$ ratio $\geq 1$, akan tetapi pendapatan usahatani tumpangsari tembakau rakyat dengan cabai lebih besar daripada usahatani monokultur tembakau rakyat. Pada usahatani monokultur tembakau rakyat nilai $\mathrm{R} / \mathrm{C}$ ratio 1,38 artinya dengan biaya input sebesar $\mathrm{Rp} .1,00$ maka akan memberikan penerimaan sebesar Rp.1,38. Pada usahatani tumpangsari tembakau rakyat dengan cabai nilai $\mathrm{R} / \mathrm{C}$ ratio 4,38 artinya dengan biaya input sebesar Rp.1,00 maka akan memberikan penerimaan sebesar Rp.4,38. 
Hal ini sejalan dengan hasil penelitian yang telah dilakukan oleh Putri (2011) menunjukkan bahwa pendapatan usahatani tumpangsari jagung-kacang tanah lebih besar daraipada pendapatan usahatani monokultur jagung. serta sejalan dengan hasil penelitian Khasanah (2016) menunjukkan bahwa rata-rata pendapatan tumpangsari ubikayu-kacang tanah lebih tinggi dibandingkan dengan monokultur ubikayu.

\section{Hasil Uji T Biaya Produksi, Pendapatan dan Efisiensi Usahatani Monokultur Tembakau Rakyat dan Tumpangsari Tembakau Rakyat dengan Cabai di Kecamatan Pringgabaya Kabupaten Lombok Timur, Tahun 2016}

Sebelum melakukan uji t terlebih dahulu dilakukan uji F untuk mengetahui apakah varians kedua sampel homogen atau tidak homogen antara biaya, pendapatan dan efisiensi usahatani monokultur tembakau rakyat dan tumpangsari tembakau rakyat dengan cabai. Hasil perhitungan uji F dari microsoft excel 2017 dengan taraf kesalahan $5 \%$ bahwa biaya ( $\mathrm{F}$ hitung $0,459<\mathrm{F}$ tabel 0,537 ), pendapatan ( $\mathrm{F}$ hitung $0,015<\mathrm{F}$ tabel 0,537), dan efisiensi ( $\mathrm{F}$ hitung $0,235<\mathrm{F}$ tabel 0,537). Hal ini menunjukkan bahwa $\mathrm{F}$ hitung biaya, pendapatan dan efisiensi lebih kecil daripada $\mathrm{F}$ tabel yang artinya kedua varians sampel homogeny.

\section{Faktor-Faktor yang Mempengaruhi Petani dalam Memilih Pola Tanam pada Usahatani Tembakau Rakyat}

Faktor-faktor yang mempengaruhi petani didaerah penelitian dalam memilih pola tanam usahatani monokultur tembakau rakyat antara lain:

1. Pasaran tembakau

2. Perhitungan biaya

3. Agar cepat tanam padi (kejar tanam balit)

4. Jenis tanah

5. Tidak pernah campur dengan cabai

6. Agar fokus sama satu tanaman

7. Usaha dan faktor dari bos (pengaruh dari bos),

8. Topografi

9. Modal

Sedangkan faktor-faktor yang mempengaruhi petani memilih pola tanam usahatani tumpangsari tembakau rakyat dengan cabai antara lain:

1. Jenis tanah

2. Topografi

3. Produksi tinggi dan memberi keuntungan besar,

4. Pasaran tembakau dan cabai

5. Musim serta hemat waktu dan lahan. 


\section{KESIMPULAN DAN SARAN}

\section{Kesimpulan}

Berdasarkan hasil pembahasan tersebut, maka dapat ditarik kesimpulan sebagai berikut: (1) Pendapatan usahatani tumpangsari tembakau rakyat dengan cabai lebih besar daripada usahatani monokultur tembakau rakyat yaitu dengan perbandingan 13,34 kali lebih besar pendapatan usahatani tumpangsari tembakau rakyat dengan cabai dari usahatani monokultur tembakau rakyat. (2) Nilai R/C ratio pada usahatani tumpangsari tembakau rakyat dengan cabai sebesar 4,38 dan monokultur tembakau sebesar 1,38 dengan selisish 3,00. Kedua pola tanam tersebut menunjukkan layak untuk diusahakan karena masing-masing $\mathrm{R} / \mathrm{C}$ ratio $\geq$ 1, akan tetapi pendapatan usahatani tumpangsari tembakau rakyat dengan cabai lebih besar daripada usahatani monokultur tembakau rakyat. (3) Faktor-faktor yang mempengaruhi petani dalam memilih pola tanam pada usahatani tembakau rakyat antara lain pasaran tembakau, perhitungan biaya, jenis tanah, topografi, usaha dan faktor dari bos usaha (pengaruh dari bos), musim, produksi dan keuntungan, waktu dan luas lahan.

\section{Saran}

Berdasarkan hasil penelitian pada usahatani tembakau rakayat di Kecamatan Pringgabaya Kabupaten Lombok Timur, maka dapat disarankan bahwa: (1) Berdasarkan masalah yang dihadapi petani yaitu ketidak cocokan antara jenis tanaman dengan tanah yang dikelola, disebabkan tanah yang dikelola merupakan tanah yang keras. Petani diharapkan untuk melakukan mengemburan tanah menggunakan pupuk organik sehingga dengan tekstur dan struktur tanah yang gembur petani dapat melakukan tumpangsari. (2) Pemerintah khususnya petugas penyuluh lapang lebih berperan aktif untuk memotivasi petani agar mau menggunakan pola tanam tumpangsari tembakau rakyat dengan cabai dan memberikan pengetahuan tentang budidaya tumpangsari tembakau rakyat dengan cabai serta memberikan solusi dari berbagai permasalahan yang petani hadapi sehingga kedua tanaman dapat tumbuh dengan optimal dan berproduksi lebih tinggi. 


\section{DAFTAR PUSTAKA}

Anonim. 1998. Pola Tumpangsari Kencur dengan Jagung dan Kacang Tanah dilahan Kering. Departemen Pertanian. Bahan Penelitian dan Pengembangan Pertanian. Balai Pengkajian Teknologi Pangan Pertanian Ungaran.

Beets, W.C. 1982. Multiple Cropping And Tropical Farming Systems. Gower Publishing Company Limited. England. 156p.

BPS Provinsi NTB. 2016. Kecamatan Pringgabaya Dalam Angka2015. BPS Provinsi NTB. Mataram

Gomez, A.A. dan K.A. Gomez. 1983. Multiple cropping in the humid tropic of asia. International development research centre. Ottawa. 248 p.

Hanum C. 2008. Tehnik Budidaya Tanaman Jilid 3. Buku teks SMK, Jakarta. http://www.ilmuku.com/file.php/1/Pustaka/Buku_Diknas/SMK/Pertanian/Tek nik_Budidaya_Tanaman_Jilid_3.pdf. [23 Januari 2017]

Khasanah N. 2016. Analisis Komparatif Monokultur Ubikayau dengan Tumpangsari Ubkayu-Kacang Tanah di Banyumas. Jurnal online. Fakultas pertanian. Universitas Janabadra Yogyakarta.

Permanasari I., Kastono D. 2012. Pertumbuhan Tumpangsari Jagung dan Kedelai pada Perbedaan Waktu Tanam dan Pemangkasan Jagung. Yogyakarta.http://Ejournal.UinSuska.Ac.Id/Index.Php/Agroteknologi/Article/View/90

Putri M.P. 2011.Analisis Komparatif Usahatani Tumpangsari Jagung-Kacang Tanah dan Monokultur Jagung di Kabupaten Wonogir. Skripsi online. Universitas Sebelas Maret. Surakarta. http://eprints.uns.ac.id/5992/1/205781111201111371.pdf.

Robis B. 2016. Analisis Komparatif Usaha Agroindustri Gula Aren di Kecamatan Gunungsari Kabupaten Lombok Barat. Skripsi. Fakultas pertanian.Universitas Mataram

Soekartawi.1995. Analisis Usahatani. Universitas Indonesia (UI-Press).Jakarta.

Suratiyah K. 2006. Ilmu Usahatani. Penebar Swadaya. Jakarta. 
